\title{
Methodology of The Initial Stage of The Preparation of The Master's Thesis on Criminal Law
}

\author{
Alexander M. Pleshakov ${ }^{1 *}$, and Gennadiy S. Shkabin ${ }^{2}$ \\ ${ }^{1}$ Moscow University of the Ministry of Internal Affairs of Russia named after V.Ya. Kikotya, \\ Department of Criminal Law, Moscow, Russia \\ ${ }^{2}$ Federal Budgetary Institution of Scientific Research Institute of the Federal Penitentiary Service, \\ Research Center (SIC), Moscow, Russia
}

\begin{abstract}
The modern legal system of any state imposes high requirements to specialists in this field, primarily related to the use of large amounts of information in the work. In this regard, the scientific work of students, aimed at forming the need for research activities, becomes particularly relevant. One of its final stages is the preparation of a master's thesis. Scientific and pedagogical experience of the authors allows stating that the majority of applicants face difficulties in choosing and justifying the topic of the research. The article considers methodological approaches to determining the boundaries and the volume of study of the material, its generalization, and formulation of the title of the thesis. The mechanisms of determination of social conditionality, elaboration, object, and subject of the forthcoming dissertation on criminal law are investigated. The objectives are to pro-vide the reader with an accessible mechanism for selecting the topic of scientific work, justifying its relevance, methodology, and setting goals and objectives. Results of work are expressed in the identification of methodological problems that arise in the course of writing the master's thesis, as well as recommendations on the organization of the initial stage of the thesis preparation.
\end{abstract}

\section{Introduction}

The master's thesis on criminal law is a qualification form of research work, which usually simulates already known practical and theoretical problems and offers their original solution. As a creative work, it should have internal unity [1]. Its successful defense means that the author qualifies as a person capable of research activity. At the same time, the role of the scientific supervisor is to coordinate the work of the graduate student, help in developing the methodology, and organize the research [2]. How-ever, the student is the one responsible for the quality of the thesis [3].

The materials of the dissertation are extracted from the sphere of theoretical and empirical knowledge [4]. Firstly, it is the already published scientific texts in monographs, articles,

\footnotetext{
* Corresponding author: pam7185@ya.ru
} 
dissertations, in the Internet telecommunication network, etc.; in historical documents; in foreign literature, etc. It is also illustrative materials - published examples from judicial and investigative practice, charts, diagrams, schemes, formulas, tables, Latin designations, etc. Such texts contain what is called the language of criminal law science. Secondly, it is the working materials, which are obtained empirically, i.e. the method is based on a consistent description of facts of criminal and legal nature. The generalization and analysis of this information make it suitable for use in the text of the thesis.

The objective of the study is to present the author's algorithm of the initial stage of preparing a master's thesis on criminal law. The tasks are to develop methods for selecting the topic of the thesis, justifying its relevance and scientific validity, as well as the formulation of the object and subject of the master's research.

\section{Methods}

The methodological basis is the logical-legal and comparative-legal research methods. They are based on system analysis of scientific works of both Russian and foreign experts in the field of criminal law and the organization of scientific activity.

\section{Results and discussion}

The choice of the topic and the definition of the title of the thesis is crucial for the applicant. This question should not be approached spontaneously, suddenly, intuitively, or guided by the principle "like - dislike" [5]. It is very important to study private problem situations that arise in judicial and investigative practice to combat specific criminal offenses and publications on these topics. This is due to the fact that a thesis on criminal law is always a study of applied nature, i.e. it is intended, in the end, to solve practical problems.

The applicant should first generalize literary sources, including international databases 6], using, for example, such resources as Google Scholar and Mendeley [7]. The publications must be distinguished by their novelty [8]. This is the first step in choosing a topic. Ownership of this information even in an approximate volume allows forming one's own preference [9]. The author decides for oneself in which direction one is going to work: whether it will be a thesis on the General or Special Part of the Criminal Code of the Russian Federation, or on a topic related to other branches of law; or on comparative law; or whether it will have a criminological character, etc.

The second step in choosing a topic is determined by the individual characteristics of the applicant. Here, personal circumstances should be considered. For example, sufficient knowledge of foreign languages, perception of conversations with practitioners, consultations with teachers, and so on may also be important.

As a result, these two aspects - prior knowledge of criminal law research issues and personal aptitudes - will help to shape what is called scientific interest. Carrying out such works without interest, i.e. without curiosity and desire to penetrate the problem, becomes a boring duty and burdensome activity.

The choice of the topic determines the necessity to formulate the title of the thesis. For this purpose, it is necessary to review the catalogue (list) of all theses, previously defended in the field of scientific interests of the applicant. The title should not contain tautology neither internal nor external, for example, "criminal offence" or "legal basis of criminal responsibility", etc. The title of the thesis should be logical, consistent, and clear. The number of words in the title may be arbitrary. As experience shows, the most appropriate is to use no more than 7-11 words. 
The final choice of the topic and title of the thesis a priori assumes the justification of its relevance, the degree of theoretical development, and the identification of research goals and objectives.

When disclosing the relevance, at least four methodological components should be highlighted. Firstly, the social conditioning of the chosen topic; secondly, the problems existing in the theory of criminal law; thirdly, the contradictions in the legislative regulation of the phenomenon; and finally, the difficulties and shortcomings of law enforcement.

Consider these aspects in more detail. The sub-section on social conditionality should briefly explain why society needs to develop this very topic, i.e. relevant for the present time. This may be proved by several factors of a legal nature related to the trends in the state's criminal policy [10]. This may be a clear desire to reduce the number of people convicted for crimes of small or medium gravity or to avoid further and significant material losses, to weaken criminal repression in certain categories of cases or to increase responsibility for the most dangerous criminal offenses, to increase the opportunities for law enforcers to be relieved of criminal liability or to make wider use of the exemption from punishment, etc.

The necessity of studying a criminal law phenomenon may be determined by the number of crimes committed and the number of persons brought to criminal responsibility, regardless of whether there are many or few of them. These figures may indicate trends in law enforcement and the importance of considering them from social and ethical positions [11]. Accordingly, to substantiate the relevance of the problem, it is quite acceptable to operate with criminal statistics data. Social conditionality of the thesis can be determined by the dynamics and structure of crime, its open or latent nature, as well as by social and psychological factors, criminological information about the personality of the criminal, the mechanism of his behavior, the means or instruments of committing the crime, etc.

The relevance of the thesis is also determined by the state of legislation in the chosen field. The expediency of the research can be determined by the vague regulation of legal provisions in the disposition of the article of criminal legislation and insufficient justification for the criminalization of crimes [12]. The necessity to study may result from the large volume of legal material of blanket content and the need to understand the conceptual apparatus in relation to the criminal law. There may also be direct contradictions between criminal law provisions and legislation from related branches of law, including those contained in departmental regulations, etc.

The Plenums of the Supreme Court of the Russian Federation often provide explanations on criminal law issues. These recommendations are sometimes incomplete, sometimes contradictory or absent at all. As a result, this or that imperfection of the criminal law, lack of proper regulation or explanations from the highest judicial body of the country determine the necessity of a deeper study of the chosen direction. Establishing the reasons for the negative trends that sometimes emerge in practice requires generalization, analysis, and recommendations to overcome them.

The next aspect to be clarified is the degree of scientific development of the topic. To prepare a thesis, it is necessary to study a sufficiently large volume of published literature. The material includes other master's and candidate's theses defended earlier, as well as criminal law courses, monographs, study guides, scientific articles in journals and conference proceedings [13], and other publications. After generalization of literary sources, the systematization of problematic issues is carried out. According to the results of this work, a conclusion is made on the degree of development of the topic, and it is noted which aspects were not considered at all, which are covered controversially, not to the full extent, etc.

An important stage in the preparation of the scientific concept is the identification of the object and subject of the research. The object is the sphere of social life in which antisocial processes related to the commission of crimes take place. In most cases, it is a complex of 
relations between people about and in connection with the commission of acts that cause harm.

The subject is something that is within the boundaries of the object and should be directly studied. A subject of study may include: scientific works on criminal law (i.e. theoretical provisions contained therein); criminal law and related legislation (constitutional, civil, administrative, procedural, etc.), international legislation and norms of criminal legislation of foreign countries; federal laws and resolutions of the Plenums of the Supreme Court of the Russian Federation; statistical indicators, empirical materials, data of judicial and investigative practice, etc.

An important element is the identification of research objectives and tasks. These objectives being of applied character can be directed: on the decision of the problems connected with revealing of the public relations demanding criminal-legal regulation; with the search of new and effective methods of criminal-legal regulation and application of corresponding legal acts; with a study of social consequences of the use of standard definitions of criminal-legal character; with a study of judicial and investigative practice and the analysis of legally significant behaviour of subjects of criminal legal relations, etc.

The setting of objectives of the research also assumes the indication of concrete tasks that should be solved for the achievement of the result. It is usually done in the form of enumeration of types of the scientific process: study; reveal; establish; determine; consider; compare; analyze; develop; find out; interpret, etc.

The formation of tasks should be done as carefully as possible since the description of their solution should constitute the content of the structural elements of the work (chapters or paragraphs). This is essential because the titles of such sections are usually derived from the wording of the research objectives.

In "Justification of the thesis", it is necessary to determine those research methods that will serve as a tool (tool) in the extraction of factual material [14]. The right choice of methods and their clear presentation is a guarantee of high-quality scientific work [15]. In works on criminal law, two main methodological directions can be conventionally identified. First, it is the theoretical ways of cognition, and second, empirical generalizations. From the theoretical point of view, this is a logical-legal method (special-legal, formal-logic, dogmatic, etc.), based primarily on the logic of thinking, as well as on philosophy, dialectics, and its historical prerequisites. The method of comparative law, comparative and system analysis, historical and legal analysis, etc. should also be highlighted here.

Among the empirical methods of studying the criminal phenomenon is the method of observation and interviewing different respondents (questionnaires, interviews, etc.). They also include: analysis of documents and statistical data, a summary of law enforcement materials, etc. [16].

\section{Conclusion}

As part of the presented work, only the initial steps for the preparation of the dissertation were analyzed. At the same time, this kind of work demonstrates the qualification level of the graduate student, indicating their creative potential. Therefore, our material will allow us to lay a solid foundation for the successful preparation of the whole research and successful defense of it. Besides, our analysis can become a basis for further developments in this field.

\section{References}

1. G. Belleville, Canadian Journal of Cardiology 35(8), 945-947 (2019) 
2. L. Vos, K. Armstrong, The International Journal of Management Education 17(1), 4761 (2019)

3. S.C. Parija, N.M. Joseph, M. Parija. Dissertation Writing for Master of Science Course. In: Parija S., Kate V. (eds) Thesis Writing for Master's and Ph.D. Program (Singapore, Springer, 2018)

4. I. Laosuma, S. Kanjanawaseea, T. Pitayanon, Kasetsart Journal of Social Sciences 37(3), 138-143 (2016)

5. I.M. Smirnova, Nauka i shkola 4, 70-76 (2015)

6. R. Bolton-King, H. Kara, J. Cassella, B. Rankin, R. Morgan, S. Burke, D. Fripp, J. Kaye, Forensic Science International: Synergy 2, 60-71 (2020)

7. K. Kousha, M. Thelwall, Journal of Informetrics 13(2), 467-484 (2019)

8. S. Galianiab \& R. Gálvez, Journal of Informetrics 13(2), 738-750 (2019)

9. J. Bell, S. Waters, Doing your research project: A guide for first-time researchers (Open University Press, London, 2018).

10. N. Lacey, Criminal Law, Philosophy (2019)

11. A.W. Norrie, Modern Law Review 80(5), 955-973 (2017)

12. P. Tomlin, Criminal Law, Philosophy (2019)

13. V.P. Kuvaldin, Criminal and investigative law: problems of intersectoral relations and prospects for improvement, in Materials of the V scientific-practical conference, Moscow, Russia (2020)

14. A.E. Zhalinskiy, Ugolovnoye pravo 3, 15-21 (2000)

15. S. Gupta, Methods and Materials in a Thesis. In: Parija S., Kate V. (eds) Thesis Writing for Master's and Ph.D. Program (Singapore, Springer, 2018)

16. A.M. Pleshakov, G.S. Shkabi, Yuridicheskiye issledovaniya 12, 53-64 (2019) 